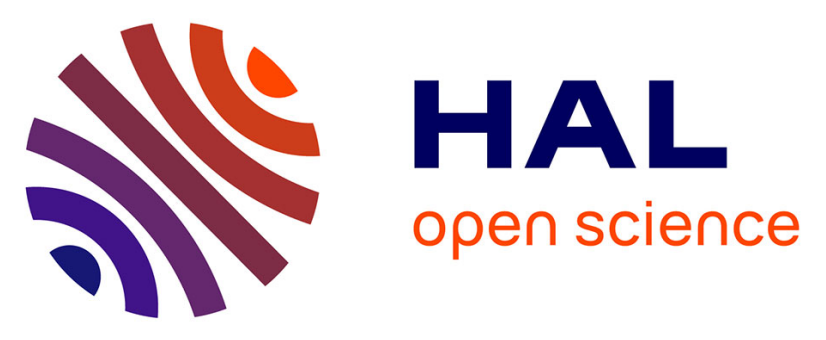

\title{
The intensive care medicine research agenda for airways, invasive and noninvasive mechanical ventilation
}

\author{
Samir Jaber, Giacomo Bellani, Lluis Blanch, Alexandre Demoule, Andrés \\ Esteban, Luciano Gattinoni, Claude Guérin, Nicholas Hill, John G. Laffey, \\ Salvatore Maurizio Maggiore, et al.
}

\section{To cite this version:}

Samir Jaber, Giacomo Bellani, Lluis Blanch, Alexandre Demoule, Andrés Esteban, et al.. The intensive care medicine research agenda for airways, invasive and noninvasive mechanical ventilation. Intensive Care Medicine, 2017, 43 (9), pp.1352-1365. 10.1007/s00134-017-4896-8 . hal-01760383

\section{HAL Id: hal-01760383 \\ https://hal.science/hal-01760383}

Submitted on 17 Dec 2019

HAL is a multi-disciplinary open access archive for the deposit and dissemination of scientific research documents, whether they are published or not. The documents may come from teaching and research institutions in France or abroad, or from public or private research centers.
L'archive ouverte pluridisciplinaire $\mathbf{H A L}$, est destinée au dépôt et à la diffusion de documents scientifiques de niveau recherche, publiés ou non, émanant des établissements d'enseignement et de recherche français ou étrangers, des laboratoires publics ou privés. 


\title{
The intensive care medicine research
}

\section{agenda for airways, invasive and noninvasive mechanical ventilation}

Samir Jaber ${ }^{* *}$, Giacomo Bellani2,3, Lluis Blanch ${ }^{4,5}$, Alexandre Demoule $^{6,7}$, Andrés Esteban ${ }^{8}$, Luciano Gattinoni ${ }^{9}$, Claude Guérin 10,11, Nicholas Hill'12, John G. Laffey ${ }^{13,14}$, Salvatore Maurizio Maggiore ${ }^{15}$, Jordi Mancebo ${ }^{16,17}$, Paul H. Mayo ${ }^{19}$, Jarrod M. Mosier ${ }^{20}$, Paolo Navalesi ${ }^{21}$, Michael Quintel ${ }^{8}$, Jean Louis Vincent ${ }^{22}$ and John J. Marini $^{18}$

\begin{abstract}
In an important sense, support of the respiratory system has been a defining characteristic of intensive care since its inception. The pace of basic and clinical research in this field has escalated over the past two decades, resulting in palpable improvement at the bedside as measured by both efficacy and outcome. As in all medical research, however, novel ideas built upon observations are continually proposed, tested, and either retained or discarded on the basis of the persuasiveness of the evidence. What follows are concise descriptions of the current standards of management practice in respiratory support, the areas of present-day uncertainty, and our suggested agenda for the near future of research aimed at testing current assumptions, probing uncertainties, and solidifying the foundation on which to base our progress to the next level.
\end{abstract}

Keywords: Acute respiratory failure, Mechanical ventilation, Non-invasive ventilation, Airways, Intubation, Weaning

\section{Introduction}

In an important sense, support of the respiratory system has been a defining characteristic of intensive care since its earliest inception. The pace of basic and clinical research in this field has escalated over the past two decades, resulting in palpable improvement at the bedside in both efficacy and outcome [1]. As in all medical research, however, novel ideas built upon prior observations are continually proposed, tested, and retained or discarded on the basis of the persuasiveness of consensus and evidence. What follows are summary descriptions of the current standards of management practice in respiratory support, the areas of present-day uncertainty, and our suggested agenda for the near future of research aimed

\footnotetext{
*Correspondence: s-jaber@chu-montpellier.fr 'Department of Anesthesiology and Critical Care Medicine B (DAR B), Saint-Eloi Hospital, University Teaching Hospital of Montpellier, INSERM U104680, avenue Augustin Fliche, 34295 Montpellier, France Full author information is available at the end of the article
}

at testing current assumptions, probing uncertainties, and solidifying our foundation for progressing to the next level.

\section{What is the current standard of care for delivering the best possible critical care in the field? \\ Artificial airway management}

Airway management in the intensive care unit (ICU) has advanced rapidly in the last decade. Delivering the best possible care involves addressing four key components to mitigate the risk to the patient: preparation, tube placement, oxygenation, and human factors. Certain granular aspects of these components are still controversial; however, these four components must be addressed to optimize safety of intubation in the ICU.

Critically ill patients have physiologic disturbances that increase their risk with even one attempt at intubation [2]. Repeated attempts increase the hazard [3]. Optimization of hemodynamics with fluid resuscitation 
and vasopressor support should be performed, as over one-third will decompensate after intubation, especially in patients with a high shock index (HR/SBP >0.8) [4]. Patients with hypoxemic acute respiratory failure (ARF) have a reduced functional residual capacity and shunt physiology, which make preoxygenation more difficult and increase the procedural hazard [5]. Noninvasive ventilation (NIV) [6], heated and humidified nasal oxygen [7-9], and flush rate oxygen by facemask improve preoxygenation compared to traditional facemask alone [5]. Intubation in the head-up position can reduce the risk of aspiration, and prior visualization of the gastric compartment by ultrasound can identify patients likely to benefit from gastric decompression [10].

Considerations regarding endotracheal tube placement include drug and device selection to maximize the chances of successful intubation without a complication [11]. Ideal drug selection depends on the patient's physiology and the operator's assessment of the potential difficulty with laryngoscopy, rescue oxygenation, or a surgical airway. Options include graded sedation with short-acting drugs like propofol [12], induction with hemodynamically neutral sedatives (ketamine or etomidate) [11], and use of a neuromuscular blocking agent after sedation [11, 13]. If an awake endoscopic approach is planned, nasal high flow oxygen (HFNC) or NIV can be useful for maintaining oxygen saturation during the procedure. Jaber et al. [14] reported that applying HFNC plus NIV before orotracheal intubation was superior to apneic preoxygenation with NIV alone. Instrument selection is more controversial. Most studies report video laryngoscopy to be superior to direct laryngoscopy [15]; however, the results of some studies indicate no difference in first attempt success $[16,17]$. If one performs direct laryngoscopy, a video laryngoscope should be available for use in the event of a first attempt failure [15]. In a randomized controlled trial (RCT) published in 2017, among 371 randomized patients in the ICU requiring intubation, video laryngoscopy compared with direct laryngoscopy did not improve first-pass orotracheal intubation rates and was associated with higher rates of severe life-threatening complications [18].

Oxygenation during laryngoscopy is potentially useful to extend apnea time and avert desaturation. Despite mixed evidence, apneic oxygenation should be performed, as it is a low-cost, low-risk, high-reward intervention [5]. In the event of a "cannot intubate-cannot oxygenate" (CICO) scenario, a supraglottic device can provide temporary rescue oxygenation if facemask ventilation proves inadequate; if $\mathrm{CICO}$ persists, airway access should be secured surgically and without delay using an open technique.

Human factors must be addressed to improve safety $[19,20]$. A team-based approach and simulation training using an algorithm should be instituted to standardize airway management as much as possible in the unpredictable context of ICU airway management. Finally, carts appropriately stocked for laryngoscopy, rescue oxygenation, and readiness to perform the surgical airway access needed for the difficult airway should be present and immediately available.

\section{Noninvasive ventilation (NIV)}

NIV is administration of mechanical ventilation without an artificial airway. In its broadest meaning, NIV includes both noninvasive continuous positive airway pressure therapy (CPAP) and positive pressure ventilation (NPPV). While the latter requires a ventilator, the former is preferentially applied by means of an adjustable flowmeter and a positive end-expiratory pressure (PEEP) valve. While often providing the same physiological benefits regarding inspiratory effort and gas exchange, NIV offers several major advantages over invasive ventilation: (1) better comfort, reducing the need for analgesic and/ or sedative drugs; (2) easier application and removal of the interface than with an endotracheal tube, allowing greater flexibility of use; and (3) preserved ability to cough, swallow, and verbally communicate. Furthermore, because NIV interferes minimally with airway protection and defenses, the risk of ventilator-associated pneumonia and other infectious complications is reduced [21], which makes this technique particularly appealing for immunosuppressed patients. However, NIV is not suitable for all patients and is contraindicated in those requiring cardiorespiratory resuscitation or who are hemodynamically unstable, are unable to protect the airway or manage airway secretions, or require high levels of airway pressure. NIV is not appropriate for those who manifest agitation, lack of cooperation, or non-hypercapnic coma. NIV outcome depends on the patient's characteristics, i.e., etiology, severity, and reversibility of ARF and co-morbidities. Success often hinges on logistic factors, such as location of treatment and team expertise, as well as on specific technical features related to ventilators and interfaces. The latter is of fundamental importance. Air-leaks are ubiquitous and, if excessive, can promote NIV failure by contributing to patient-ventilator asynchrony and discomfort [22]. They can be contained by properly choosing and applying the interface and by using ventilators equipped with dedicated NIV software capable of detecting and compensating for leaks [22]. The interface has to be comfortable enough to make NIV well tolerated. ARF severity, facial characteristics, tendency for claustrophobia, and duration of NIV application should all be considered when choosing the interface. As patients with ARF are generally mouth-breathers, full face masks are preferred initially [23]. However, there is no perfect interface 
for all patients and the choice must be individualized. Also, when prolonged, near-continuous NIV application is necessary, a rotational interface strategy should be considered [24]. The timing of NIV administration is also important. Early NIV may be used to prevent the occurrence of frank ARF and avert the need for endotracheal intubation as other measures address the precipitating cause [25]. Patient selection is crucial, aiming to avoid patients at excessive risk of NIV failure. NIV is strongly recommended for patients with hypercapnic ARF, especially in those with a chronic obstructive pulmonary disease (COPD) exacerbation [26], and ARF secondary to cardiogenic pulmonary edema [27]. NIV can facilitate the extubation of COPD patients intubated for hypercapnic ARF; however, as for all instances where NIV is used as an alternative to invasive ventilation, this application requires an ICU team highly experienced with this technique [28]. In patients at high risk of extubation failure, NIV soon after planned extubation reduces the rate of reintubation and improves overall outcomes [29]. For many patients, HFNC, a methodology that reduces breathing frequency, provides some deadspace washout, applies low level airway pressure, and may improve distribution of ventilation, appears to offer an appropriate alternative for this specific indication [30]. NIV reduces the rate of respiratory complications including reintubation in patients after high-risk surgeries [31] and chest trauma [32]. Although some patients might benefit, widespread use of NIV in de novo hypoxemic ARF, in particular those with acute respiratory distress syndrome (ARDS), is presently not advisable [33].

The emergence of NIV has clearly been of value for patients with hypercapnic respiratory failure and cardiogenic pulmonary edema, but it must be administered to selected patients using appropriate equipment in the right location by skilled and experienced staff. In the LUNG SAFE study, it has been reported that NIV was used in $15 \%$ of patients with ARDS, irrespective of severity category. NIV seems to be associated with higher ICU mortality in patients with a $\mathrm{PaO}_{2} / \mathrm{FiO}_{2}$ lower than $150 \mathrm{mmHg}$ [34].

\section{Invasive ventilation}

A primary focus of research and recommendations on invasive ventilation recently has been centered on ARDS, in which ventilation settings have been shown able to affect patient outcome (Fig. 1). The cornerstone for lung protective ventilation, deriving from the ARDS Network (ARMA) trial, remains the use of a tidal volume of $6-8 \mathrm{ml} / \mathrm{kg}$ (predicted body weight) while limiting plateau pressure below $30 \mathrm{cmH}_{2} \mathrm{O}$ [35]. More recent data suggest that a higher "driving pressure" (i.e., the difference between plateau pressure and PEEP) is the variable

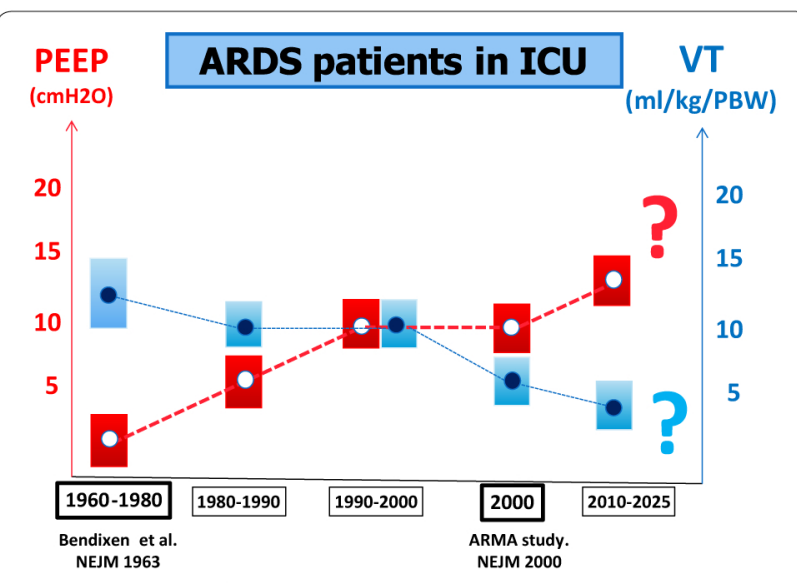

Fig. 1 Evolution of tidal volume (VT) expressed in predicted body weight (PBW) and positive end-expiratory pressure (PEEP) in $\mathrm{cm} \mathrm{H}_{2} \mathrm{O}$ in the last 50 years in ARDS patients

most strongly associated with adverse outcomes [36, 37], underlining the importance of monitoring this parameter. Adoption of protective tidal volumes in clinical practice remains suboptimal and, of greater concern, plateau pressure is measured in less than half of all patients [38]. Clinical trials concerning the setting of PEEP have been less conclusive [39-41], but meta-analyses suggest that "higher PEEP" might benefit patients with moderate/severe ARDS [42]. The panel of experts of the "ARDS definition task force" also recommended the use of "low" PEEP in mild ARDS and "higher PEEP" in moderate to severe ARDS [43]. The oxygenation response, as an index of alveolar recruitment, may be useful in titrating PEEP [44]. LUNG SAFE data on the one hand confirm that higher PEEP is associated with improved outcome [37], but on the other also show the reluctance of clinicians to increase PEEP and a tendency to favor raising the inspired oxygen fraction to correct hypoxemia [38]. The use of maneuvers to maximize alveolar recruitment has also been shown to be safe and effective in improving oxygenation when followed by an upward revision of PEEP, but their impact on outcome is unclear [45]. No convincing evidence favors either volume- or pressure-cycled ventilatory modes over the alternative [46]. Because two large RCTs showed no benefit and possible harm from high-frequency oscillatory ventilation [47, 48], its use in ARDS is not recommended.

Certain ventilatory adjuncts may confer important benefits in well-selected patients. Prone positioning favors recruitment of dorsal lung regions, improved oxygenation, and decreased ventilator-induced lung injury (VILI). The positive influence of prone positioning on survival from ARDS was recently shown [49] in patients with a $\mathrm{PaO}_{2} / \mathrm{FiO}_{2}$ lower than $150 \mathrm{mmHg}$. Optimal 
duration of prone position is uncertain, but greater than $16 \mathrm{~h}$ per day until an oxygenation benefit is no longer observed seems reasonable [49]. The same subset of ARDS patients also benefit from continuous infusion of neuromuscular blocking agents mainly during 24-48 h in the first $48 \mathrm{~h}$ on invasive ventilation, with improved survival and decreased incidence of barotrauma [50]. Although gentle spontaneous efforts may improve the distribution and efficiency of ventilation, vigorous spontaneous breathing, which acts together with airway pressure to increase transpulmonary inspiratory pressure, is discouraged. Large ongoing international RCTs are currently investigating new protocols for mechanical ventilation (MV) management (ROSE PETAL-NMB; ART and PHARLAP, etc.).

Following resolution of ARF, guidelines recommend to attempt liberation from mechanical ventilation by performing a spontaneous breathing trial in patients with cardiovascular stability (none or minimal vasopressors), no continuous sedation, and $\mathrm{PaO}_{2} / \mathrm{FiO}_{2}$ of at least $150 \mathrm{mmHg}$ with a PEEP of at most $8 \mathrm{cmH}_{2} \mathrm{O}$ [51]. While the most commonly used classification divided patients into simple, prolonged, and difficult weaning [51], a novel categorization of patients has recently been proposed, based on pragmatic definitions of separation attempts and weaning success [52]. Finally, recently published guidelines weakly recommend to use inspiratory pressure augmentation in the initial spontaneous breathing trial, and to use protocols to minimize sedation. A strong recommendation was made to use preventative NIV for high-risk patients immediately after extubation [53].

\section{What have been the major recent advances in the field? (Table 1)}

Airways and noninvasive mechanical ventilation

Useful options and improved interfaces have been developed and deployed. The mechanisms of benefit and indications for HFNC oxygen and conventional NIV in acute hypoxemic non-hypercapnic respiratory failure have been refined in recent years. In one RCT, intubation rates were similar in patients managed with HFNC, NIV administered by facemask, and standard oxygen therapy; however, mortality rates were lower with HFNC than with NIV or standard oxygen therapy, and HFNC was associated with improved comfort and less dyspnea [54]. In patients with ARDS randomized to receive NIV through helmets or face masks, the helmet group had lower intubation rates, more ventilator-free days, shorter ICU stays, and lower mortality [55]. Studies in immunocompromised patients with hypoxemic respiratory failure showed that early HFNC [56] or NIV [57] did not reduce intubation rates, duration of mechanical ventilation, hospital stay, or mortality compared with oxygen therapy alone, but another study using propensity-score

\section{Table 1 Advances of the past decade in the field of ventilation}

Preoxygenation, intubation, airways management

Optimization of preoxygenation using HFNC oxygen and/or NIV

Use of videolaryngoscope devices

Healthy lungs (or non-ARDS)

Prevention ARDS occurrence

Improved operative and perioperative ventilator management

ARDS

Early prone positioning for ARDS

Selective use of muscle relaxants for oxygenation failure

Evolution and deployment of extracorporeal gas exchange

Esophageal pressure monitoring for selected clinical applications

Refocusing VILI on driving pressure and energetics of ventilation vs conventional lung protective ventilation

Widespread awareness of need for lung protection

Weaning-extubation, sedation

Asynchrony detection, prioritization, and therapy

Extension of esophageal pressure monitoring to clinical applications

Avoidance of excessive sedation and protracted controlled ventilation

Recognition and prevention of VIDD

NIV and oxygenation

Development of improved NIV interfaces and HFNC

Dedicated NIV software and ventilators 
matching in similar patients reported that HFNC was associated with lower intubation rates, shorter ICU stays, and lower mortality rates than NIV [58]. Among postoperative patients with hypoxemic respiratory failure following abdominal surgery, use of NIV compared with standard oxygen therapy reduced the risk of tracheal reintubation within 7 days as well as the incidence of nosocomial infection [31].

Indications for noninvasive support have been better defined. Compared with conventional oxygen therapy, postextubation HFNC reduced reintubation rates in patients at low risk of reintubation [59]. In another study of patients at high risk for reintubation, the same authors reported that although reintubation rates were similar with HFNC and NIV, HFNC was associated with reduced postextubation respiratory failure and shorter ICU stays while causing no major complications [30]. Jaber et al. [14] reported that applying HFNC plus NIV before orotracheal intubation was superior to apneic preoxygenation with NIV alone. The bulk of current evidence, therefore, suggests that HFNC is a promising approach for multiple stages and indications in ARF.

\section{Invasive mechanical ventilation}

Recent years have seen better appreciation and understanding of the hazards tied to mechanical ventilation. Ventilatory strategies using low end-inspiratory plateau airway pressure, low tidal volume $\left(V_{\mathrm{T}}\right)$, and high PEEP improve survival in ARDS (Fig. 1). From the limited epidemiologic information gathered in the context of controlled tidal volume and no spontaneous breathing, driving pressure has been identified as a strong predictor of death. The observational LUNG SAFE study, which assessed how clinicians ventilate ARDS patients, reported that less than two-thirds of patients received $V_{\mathrm{T}}$ of at most $8 \mathrm{ml} / \mathrm{kg}$ of predicted body weight and $82.6 \%$ received PEEP lower than $12 \mathrm{cmH}_{2} \mathrm{O}$. Factors associated with improved survival were higher PEEP, lower peak, plateau, and driving pressures, and lower respiratory rate [37]. All these factors, together with $V_{\mathrm{T}}$, interact to increase/decrease the mechanical power transferred to lung parenchyma (Fig. 2) [60]. Recent studies conclude that lung-protective MV principles should be applied regardless of the risk of ARDS. Though intriguing, such recommendations remain controversial at the present time. Furthermore, vigorous spontaneous breathing with assisted mechanical ventilation may increase the risk of lung damage [61]; however, most patients switched to proportional assist ventilation maintain driving pressures within a range currently considered safe during controlled mechanical ventilation [62].

Patient-ventilator asynchronies occur commonly during mechanical ventilation and have been linked

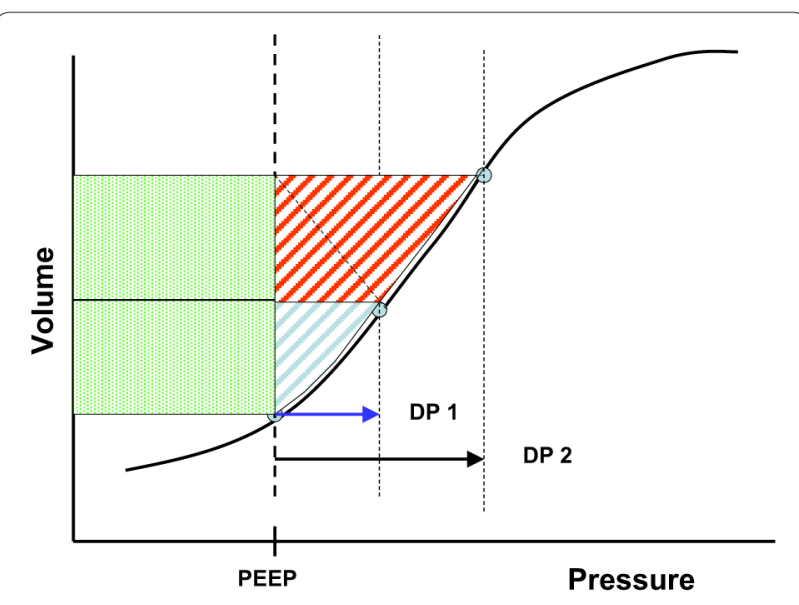

Fig. 2 Schematic relationship depicting the nonresistive components of the equation of motion that determine the energy delivered to the lung during the tidal breath. Total nonresistive ("quasi-elastic") energy imparted per cycle is the sum of the pressure-volume areas enclosed by PEEP (green shading), and by the tidal driving pressures associated with a small tidal volume (DP 1) and with a tidal volume twice as large (DP 2). Note that the tidal elastic energy area for the larger tidal volume (sum of red and blue areas) is more than twice that of the smaller tidal volume (blue hatched area). The inspiratory power exerted by the machine on the lung parenchyma (energy units per minute) is the product of cycling frequency and the respective colored energy areas. A portion of the total potential energy stored during inspiration is recovered during expiration (Modified from Marini and Jaber [94])

statistically to adverse outcomes [63]. Clusters of ineffective inspiratory efforts occurring between prolonged uneventful periods during pressure support and proportional-assist ventilation are associated with longer duration of MV and higher rates of hospital mortality. Clusters appear to predict outcomes better than the proportion of asynchronies occurring during the MV period, suggesting the need to continuously monitor machine response and neural breathing rhythm [64]. Low-dose sedatives may reduce respiratory drive and promote triggering of asynchrony; however, dexmedetomidine has been associated with fewer asynchronies than propofol at similar levels of consciousness [65].

\section{What are the common beliefs that have been contradicted by recent trials?}

Over the past few years, some large trials have provided results that were in contradiction with prevailing belief in the fields of airways, NIV, and invasive mechanical ventilation. Here, we discuss three specific topics: corticosteroids in acute exacerbations of COPD, NIV for ARF in immunocompromised hosts, and high frequency oscillation ventilation (HFOV) in ARDS.

In addition to bronchodilators, corticosteroids are recommended during COPD exacerbations to decrease 
local bronchial inflammation and airway obstruction [66]. Studies supporting corticosteroid treatment in these patients, however, have been conducted outside the ICU or in patients with disease of mild-to-moderate severity who do not require mechanical ventilation. Two RCTs were performed in patients with severe exacerbations requiring ICU admission. Both studies were underpowered. The first one [67] showed that intravenous methylprednisolone $(0.5 \mathrm{mg} / \mathrm{kg})$ was associated with a reduction in the duration of mechanical ventilation (3 vs 4 days) and in the NIV failure rate ( $0 \%$ vs $37 \%$ ). On the contrary, the second trial [68] failed to demonstrate any beneficial effect of oral prednisone $(1 \mathrm{mg} / \mathrm{kg})$ on ICU mortality, duration of mechanical ventilation, and ICU length of stay, but did indicate that steroids increased the number of hyperglycemic episodes. A comprehensive meta-analysis [69], pooling studies performed in non-critically ill and critically ill patients, showed benefit from corticosteroids on treatment success rate only in non-critically ill patients.

NIV has been proven effective to reduce intubation and mortality rates, mainly in acute on chronic respiratory failure and in acute cardiogenic pulmonary edema and, to a lesser extent, in de novo ARF [70]. In the early 2000s, two RCT performed in single centers reported clear benefit from NIV for ARF in immunocompromised hosts, both in patients with hematological diseases [71] and in patients with solid organ transplants [72]. These results had a strong influence on guidelines and on clinical practice. Recently, a large multicenter trial was performed [57] in patients with various causes of immunosuppression (mostly hematologic malignancies and solid tumors) to compare the effects of NIV versus oxygen alone on clinical outcomes. In this study, NIV did not reduce intubation rate, mortality, or length of stay. The generally improved prognosis of immunocompromised patients treated in the ICU may help to explain these findings. Although these results do not contraindicate NIV in immunocompromised patients with ARF, they suggest that the benefit of NIV in this population is less dramatic than previously observed.

HFOV delivers small VT at high respiratory rates and at high mean airway pressure, with the aim to protect the lungs from overdistension and derecruitment [73]. The idea behind this approach is that targeting an "open lung" and ventilating with very low tidal volumes may enhance lung protection as compared to conventional strategies. Preliminary data in ARDS patients were encouraging [74]. Two recent studies, however, have contradicted this belief. The OSCILLATE trial [75] was prematurely aborted after 548 patients had been randomized because of excess hospital mortality in the HFOV group as compared to the control group treated with conventional ventilation $(47 \%$ vs $35 \%, p<0.005)$. Doses of sedatives were higher and there was a trend for more barotrauma in the HFOV group (18\% vs $13 \%)$. Finally, mean airway pressure was higher with HFOV compared to controls (31 vs $24 \mathrm{cmH}_{2} \mathrm{O}$ ), a characteristic that likely caused hemodynamic compromise. (Indeed HFOV patients received vasoactive/inotropic drugs more frequently and in higher doses.) Together, these shortcomings may explain the increased mortality. The OSCAR trial [76], mainly conducted in centers with limited or no experience with the HFOV technique and treating patients with ARDS of lower severity, did not show differences in 30-day mortality between HFOV and usual care $(42 \%$ vs $41 \%$ ). Why HFOV did not work in these trials potentially can be attributed to numerous factors. One is ineffective "recruitment" (as much as $24 \%$ of the ARDS lung remains non-recruitable even at pressures of $45 \mathrm{cmH}_{2} \mathrm{O}$ [76]). High mean airway pressures resulted in sustained overdistension of healthy lung parenchyma, afterloading the right ventricle and impeding venous return by elevating intrathoracic pressure. Other possibilities include the high amount of "energy" dissipated in heterogeneous ARDS lungs (due to the extremely high respiratory rates during HFOV), and the difficulties presented by managing a ventilator mode with unusual settings and lack of conventional alarms. These data remind us that providing optimal ventilator settings in ARDS is not an easy task and suggest that conventional treatment (with moderate to high PEEP levels, low tidal volumes, and moderate driving airway pressures, as happened in the OSCILLATE usual care group) is currently a reasonable approach to lung protection. Today one could argue that prone position would be strongly recommended in this scenario. Tomorrow, one could speculate that prone position will be implemented with extracorporeal gas exchange techniques to further improve lung protection while maintaining adequate gas exchange and minimizing the physical and hemodynamic impact of mechanical ventilation.

\section{What are remaining areas of uncertainty?}

In the field of intensive care medicine the primacy of "nihil nocere" and superiority of treatment outcome should guide the quest for certainty. As exemplified by the selected examples that follow, most uncertainties in the field of respiratory support arise as to how to individually tailor treatment in such a way that a patient has the best possible chance to survive at the lowest human cost.

\section{Artificial airways}

Development and widespread use of percutaneous tracheostomy (PDT) has led to recent increases in the numbers of tracheostomies performed and of the published 
studies dealing with this procedure [77-79]. The belief that early tracheostomy might reduce the rate of pneumonias and consequently improve outcome for invasively ventilated patients has been contradicted. In contrast, a RCT has demonstrated that some patients treated with an "early" tracheostomy receive this intervention unnecessarily, imposing additional risk without benefit for the individual patient [80]. Long-term outcome of tracheostomized patients is poorly studied, raising the troubling question of whether the performance of a tracheostomy often acts more as a tool for directing patients in the medical system than as an indicated measure for the individual patient $[81,82]$.

\section{Natural airways}

Optimal dosing and timing remain unclear for the gravely ill patient; studies supporting corticosteroid use have not been directed toward those requiring invasive mechanical ventilation. Indeed, a recent meta-analysis [69] indicated benefit of corticosteroids on treatment success rate in non-critically ill patients, whereas no consistent benefit accrued in critically ill patients. Given such inconsistent results, whether steroids should be used, in which doses, and for what duration remain open-ended questions.

\section{Invasive mechanical ventilation}

Reduction or avoidance of VILI has become a leading focus of respiratory support [81, 83]. Success and assertiveness of this directive have two primary bases: first, a plausible theory in which the key determinants of mechanical ventilation (pressures, volume, PEEP) play defined and reproducible roles; and second, the demonstration by a large RCT that limiting one of the determinants (tidal volume, TV) reduces mortality in mechanically ventilated patients [35]. The VT-associated delta ("driving") pressure has been shown predictive for mortality in a retrospective analysis [36]. However, factors other than the characteristics of the individual tidal cycle determine the occurrence and severity of VILI. Recently, it was suggested that an inclusive single variable, the mechanical power, might summarize all mechanical stressors shown experimentally and by observation to injure the lungs during mechanical ventilation [60]. The mechanical power in this case is primarily the product of VT, driving pressure, and respiratory rate. Uncertainty remains regarding whether mechanical power, though measurable, should help guide machine settings. Moreover in weighing relative risks and benefits of medications and procedures for the individual, the value and timing of implementing neuromuscular paralysis or extracorporeal gas exchange so as to reduce transmission of power to the lungs remain undetermined. Although extracorporeal gas exchange (ECMO) techniques are still undergoing safety testing and refinement, one could speculate that they might be implemented together with prone positioning to further improve lung protection and maintain adequate gas exchange while minimizing the demands that intensify the physical and hemodynamic impacts of mechanical ventilation.

HFOV delivers small VT at high respiratory rates and high mean airway pressures, with the aim to protect the lungs from tidal overdistension and derecruitment [73]. Targeting an "open lung" and ventilating with very low tidal volumes theoretically should enhance lung protection as compared to conventional strategies.

\section{Noninvasive ventilation (NIV)}

The clear role of NIV in avoiding an artificial airway for COPD and cardiogenic pulmonary edema [84] has extended its use to states, diseases, and entities in which beneficial effects are questionable [34, 85]. NIV uses a different interface but does, as with MV, transmit mechanical power to the lungs and can evoke asynchrony. Moreover, the pressure-targeted nature of NIV leaves transpulmonary pressure and tidal volume unregulated. Such drawbacks of NIV, as well as its relative limitations and advantages for treating severe acute respiratory support, raise the question of whether extracorporeal gas exchange can complement its use so as to avoid or minimize the need for invasive ventilation $[86,87]$.

\section{What the international group of experts recommend as the top 10 studies/trials to be done in the next 10 years and what are expected outcomes/results of these trials}

\section{Recommended studies for the next decade}

Important lessons have been learned in constructing the research base for present-day management of ARF. Foremost among these is that the populations we treat are diverse and that the definitions with which we identify our patients and select subjects for trials are imprecise. Moreover, complexity of the syndromes we confront as well as interactions among the co-interventions we apply weaken traditional reductionist approaches that focus on single (sometimes inappropriate) target variables while too often ignoring important confounders and applying patient inclusion and exclusion criteria of questionable validity. Understanding the etiologic cause of acute illness and potential consequences of intervention should ideally precede the implementation of such symptomatic treatments as mechanical ventilation and/or hemodynamic optimization. Heterogeneity, non-individualized dosing, and uncertain duration of application bedevil standardized responses and degrade the power of the study to discriminate between treatment effects. In this 
ICU context of patient diversity, imprecise definitions, and multiple dynamically interactive variables, reductionist thinking takes us only so far; so-called emergent phenomena often yield surprising and even misleading results [88]. Consequently, admirable efforts have frequently given rise to costly, slowly completed, and inconclusive RCT studies, even as they generated interesting questions and observations that helped refocus the process. Innovative approaches, such as the adaptive trial designs shown helpful in other medical disciplines [89], will likely improve and expedite RCT execution. Yet, whatever the contribution of these newer study architectures and analytic methods might be, direct application of population-based results to the individual are liable to remain problematic in such a complex, ill-defined, and heterogeneous setting for all but the most obvious questions of interest; therefore, the recent emphasis on precision medicine and personalization of care is especially relevant to our currently syndrome-based discipline [90].

Treatment timing and intensity as well as condition severity often determine the value or peril of the tested intervention. Several important examples pertain to ventilation: the level of PEEP applied to a given patient may help or harm, depending on recruitability, driving pressure, and pressure baseline [36]. Paralytics may be life preserving during the earliest stage of severe ARDS [50] but lead to disability and diaphragmatic weakness (VIDD) if unnecessarily sustained [91]. Prone positioning, a key adjunct to ventilating severe ARDS, is a potentially life-saving intervention [49] whose utility is dependent on stage, duration, and perhaps recruitability $[92,93]$.

Focusing on the static characteristics of the individual tidal cycle (i.e., PEEP, plateau, and VT) is clearly a restrictive approach toward intervening in a complex VILI process that has been shown by laboratory experimentation to be strongly influenced by cycling frequency, flow rate, flow contour, and vascular pressure [94]. Therefore, future studies may need to take into account various dynamic as well as static mechanical elements as well as non-mechanical co-factors that modulate the straining effect.

Investigators, educators, and clinicians tend to skip logical steps and unwisely extrapolate as we hasten to apply the results of the latest RCT or meta-analyses that indicate what to do without clear biological plausibility. It is sobering that uncorroborated RCTs sometimes produce unanticipated but convincing results that have strong but temporary impact as they are overturned by subsequent contradictory RCTs or meta-analyses. While there is an unquestioned association between high-pressure ventilation strategies and mortality, for example the ARMA study [35], we do not have incontrovertible evidence that a less favored approach actually retards lung healing or inflicts VILI. If it does, how do such consequences for lung functioning lead to death? Adequate gas exchange, the lung's primary function, can nearly always be accomplished and maintained. Mechanistic linkage is even less clear for adverse outcomes associated with patient-ventilator asynchrony [63] and for the putative benefits of intraoperative lung protection applied to patients without overt lung disease so as to avoid undesired outcomes that occur days later [95]. The wisdom of attempting to apply population-based data to a specific individual without understanding the circumstances and mechanisms that drove the study results can be misguided. In the field of respiratory support it is reasonable to question whether RCTs should be undertaken without a design underpinned by a strong mechanistic rationale [96]. Prediction of expected outcomes from clinical trials is hazardous unless underpinned by such a foundation or by an already convincing body of observational studies, biological plausibility, and clinical experience.

In the near future, progress toward improved RCTs may be aided by recently developed tools that help in patient selection, personalization, and study conduct (Table 2) [90]. Such innovations include "big data" analysis to determine key interactive variables and to refine appropriate phenotypes (Fig. 3) [97], biomarkers of individual responsiveness and hazard (proteomics, metabolomics, etc.), whole genome profiling [98], and innovative trial designs (e.g., the aforementioned adaptive approach) [89] and analytics (e.g., recursive partitioning). These newer tools may allow us eventually to address vitally important but understudied questions relevant to respiratory support, such as innate adaptability and resilience to critical illness, respiratory muscle conditioning, VIDD avoidance [83], and rehabilitation [99]. The causative impact of current ventilator approaches on chronic critical illness is likely to be profound, but with few exceptions ideal management approaches currently remain undefined. It is unclear, for example, whether our traditional focus upon achieving stability remains in the best interest of the patient after the initial period of rescue has passed. Maintaining normal physiologic targets, e.g.,

\section{Table 2 Tools for personalizing and improving efficiency of clinical studies}

Whole genome characterization

"Big data" analysis

Quantitative biomarkers

Mechanism-driven protocols

Innovative trial designs and analyses

Education, training-simulation 


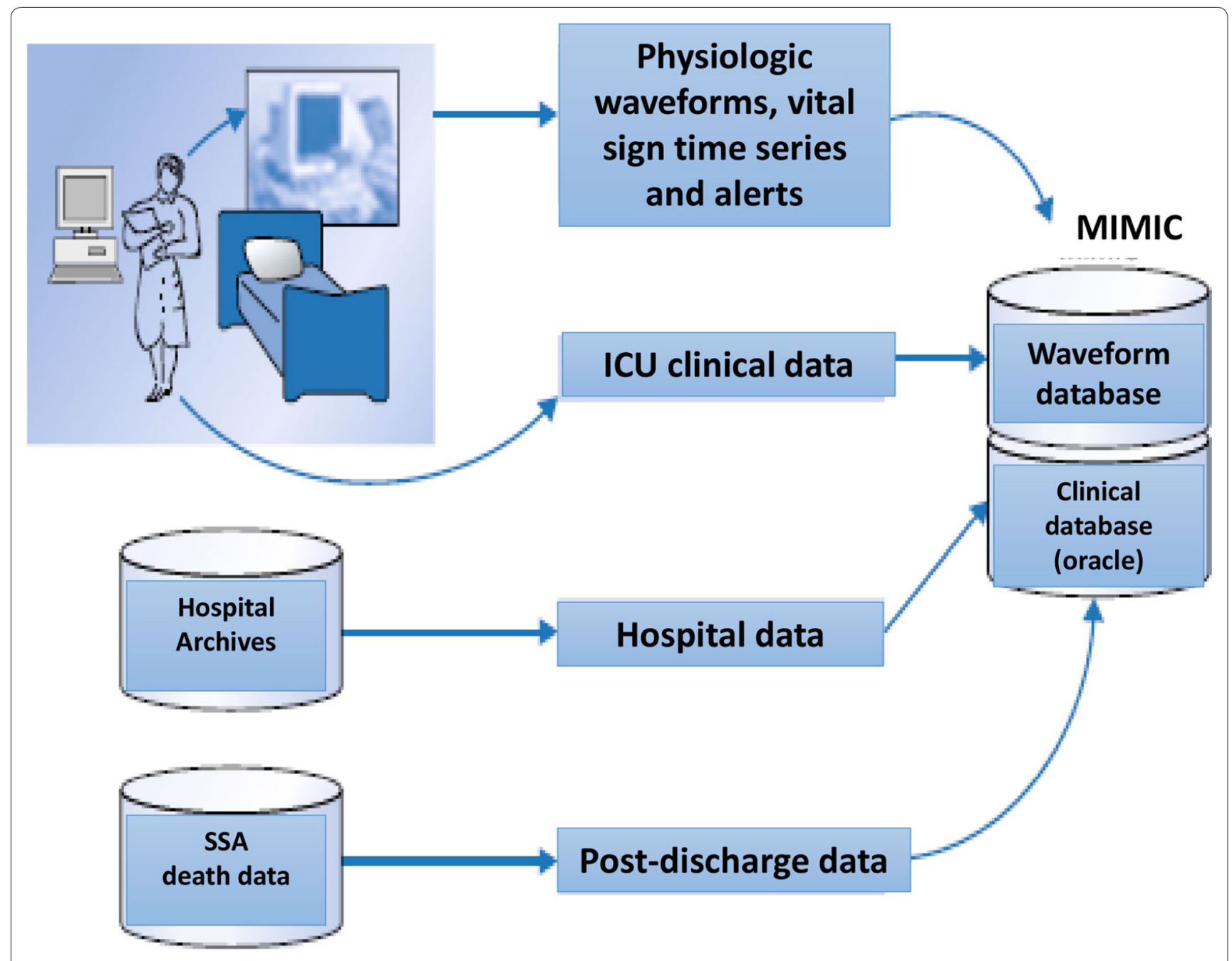

\section{Institute of Tectinology).}

Fig. 3 "Big database" collection in an ICU environment. Phenotypes determined from analyses of such data could theoretically facilitate personalization of care and improve selection of subjects for research trials (from Ghassemi et al. [97])

for oxygen saturation, may obligate use of noxious therapies [100]. Could it be that we need to monitor patient progress and capability more closely to encourage reconditioning at an earlier stage of illness, rather than to support too much for too long? [101].

Unlike laboratory investigations, RCTs seldom define disease mechanisms but can potentially contribute to our understanding of them. Conversely, comprehending underlying mechanisms and taking thoughtful account of solid experimental and observational data is often key to developing effective trial design. Although the number of unanswered and important questions is boundless, intriguing recent observations and RCT results help set the near-term direction for our research efforts (Table 3). Over the next decade, important areas of investigation, addressed either in the laboratory or at the bedside, should include defining the roles of spontaneous breathing efforts in preventing or exacerbating VILI [61], discovering the true basis for the association of asynchrony and adverse patient outcome $[63,102]$, and determining the contributions of flow contour, breathing pattern, and minute ventilation to the hazard safety that accrues to mechanical ventilation [94]. The vexing question of how best to set PEEP may eventually yield to the mechanismdefined design of the RCT that explores it. The need to record transpulmonary pressure for PEEP selection and 
Value and limitations of transpulmonary pressure

Energetics of ventilation: roles of PEEP, plateau, driving pressure, power

Relative hazards of increased PEEP vs increased $\mathrm{FiO}_{2}$

Imaging-guided ventilatory management (CT scan at bedside and/or ultrasound) Indications and contraindications for spontaneous breathing

Timing the transition from full to partial ventilator support

Mechanisms of benefit from pharmaco-paralytic agents

Evaluation new specific drugs

Prevention and exacerbation of VIDD

Impact of ventilatory pattern, monotony, and variation

Prevention of ARDS occurrence in healthy lung patients

When and who should receive lung protective ventilation?

Hazards and mechanisms of synchrony

Extrapulmonary gas exchange in avoiding and weaning from invasive ventilation

Defining the relative values of NIV and high flow nasal $\mathrm{O}_{2}$

Impact of monitoring lung biomarkers in selected populations

Impact of auto-adjusting ventilatory modes

lung strain assessment should be settled [103]. Whether and how ventilator support itself encourages chronic critical illness urgently deserves attention [104]. Both basic and clinical studies need to be performed to test competing hypotheses regarding observable and modifiable variables that may act as the proximate mechanical impetus to VILI, such as transpulmonary driving pressure [103, 105], power delivery [60], and strain intensity [94]. Further studies are needed to confirm the causative influence of driving pressure and the value of pharmacoparalysis, as well as to resolve questions regarding their mechanisms of harm and benefit. Finally, the full potential for extracorporeal techniques coupled to NIV or HFNC to avert the need for intubation should be explored as these newer technologies are refined.

\section{Conclusion}

Effects of interventions depend on timing and individual predispositions to response and hazard $[19,20]$. Well-executed clinical trials designed without appropriate selection criteria in mind may be relevant to the population studied but are open to misinterpretation and misapplication in practice. Powerful new tools for conducting sophisticated RCTs and implementing precise, personalized medicine, such as "big data" analysis, whole genome testing, and closed loop decision support hold immense potential to reshape and reform both our research efforts and our daily practice. Whatever the sophistication of decision supports, however, the ICU practitioner, primed by guidance of the research base and alert to the integrating feedback that only the individual patient's bedside response can provide, will remain instrumental to the delivery of high-quality respiratory system support.

\section{Author details}

1 Department of Anesthesiology and Critical Care Medicine B (DAR B), Saint-Eloi Hospital, University Teaching Hospital of Montpellier, INSERM U104680, avenue Augustin Fliche, 34295 Montpellier, France. ${ }^{2}$ Department of Medicine and Surgery, University of Milan-Bicocca, Monza, Italy. ${ }^{3}$ Department of Emergency and Intensive Care, San Gerardo Hospital, Monza, Italy. ${ }^{4}$ Critical Care Center, Parc Tauli University Hospital, Institut de Investigació i Innovació Parc Taulí, I3PT, Universitat Autònoma de Barcelona, Sabadell, Spain. ${ }^{5}$ CIBER Enfermedades Respiratorias, ISCIII, Madrid, Spain. ${ }^{6}$ UMRS1158 Neurophysiologie Respiratoire Expérimentale et Clinique, Sorbonne Universités, UPMC Univ Paris 06, INSERM, Paris, France. ${ }^{7}$ Service de Pneumologie et Réanimation Médicale (Département "R3S"), AP-HP, Groupe Hospitalier Pitié-Salpêtrière Charles Foix, 75013 Paris,

France. ${ }^{8}$ Hospital Universitario de Getafe, CIBER de Enfermedades Respiratorias, Madrid, Spain. ${ }^{9}$ Department of Anesthesiology, Emergency and Intensive Care Medicine, University of Göttingen, Göttingen, Germany. ${ }^{10}$ Service de réanimation médicale, Hopital de la croix rousse, Lyon, France. ${ }^{17}$ Université de Lyon and INSERM 955, Créteil, France. ${ }^{12}$ Pulmonary Division APC 479A, Rhode Island Hospital, 593 Eddy Street, Providence, RI 02903, USA. ${ }^{13}$ Departments of Anesthesia and Critical Care Medicine, St Michael's Hospital, Critical Illness and Injury Research Centre, Keenan Research Centre for Biomedical Science, Toronto, Canada. ${ }^{14}$ Departments of Anesthesia, Physiology and Interdepartmental Division of Critical Care Medicine, University of Toronto, Toronto, Canada. ${ }^{15}$ Department of Medical, Oral and Biotechnological Sciences, School of Medicine and Health Sciences, Section of Anesthesia, Analgesia, Perioperative and Intensive Care, "SS. Annunziata"Hospital, "Gabriele d'Annunzio" University of Chieti-Pescara, Chieti, Italy. ${ }^{16}$ Department of Medicine, University of Montréal, Division of Intensive Care at Centre Hospitalier Université de Montréal (CHUM), Centre Recherche CHUM, Montréal, QC, Canada. ${ }^{17}$ Institut de Recerca Hospital de St Pau, Barcelona, Spain. ${ }^{18}$ Punmonary and Critical Care Medicine, Regions Hospital, University of Minnesota, Minneapolis/Saint Paul, MN, USA. ${ }^{19}$ Division of Pulmonary, Critical Care and Sleep Medicine, Northwell Health NSUH/LIJ, New Hyde Park, NY 11040, USA. ${ }^{20}$ Department of Emergency Medicine, Department of Medicine, Division of Pulmonary, Allergy, Critical Care, and Sleep, University of Arizona, Tucson, AZ, USA. ${ }^{21}$ Department of Medical and Surgical Sciences, Anesthesia and Intensive Care, Magna Graecia University, Catanzaro, Italy. ${ }^{22}$ Department of Intensive Care, Erasme University Hospital, Université Libre de Bruxelles, Brussels, Belgium. 


\section{Compliance with ethical standards}

\section{Conflicts of interest}

Dr Blanch is inventor of a US patent owned by Corporació Sanitaria Parc Taulí: "Method and system for managing related patient parameters provided by a monitoring device," US Patent No. 12/538,940. He owns stock options in BetterCare S.L., a research and development start-up of Corporació Sanitària Parc Taulí (Spain). Dr Demoule reports personal fees from Maquet, grants, personal fees, and non-financial support from Covidien, personal fees from MSD, grants and non-financial support from Philips, non-financial support from Drager, grants from Resmed, and personal fees from Fisher and Paykel, all outside the submitted work. Dr Jaber reports receiving consulting fees from Drager, Hamilton, Maquet, and Fisher and Paykel. Dr Maggiore is the principal investigator of the RINO trial (nasal high-flow vs Venturi mask after extubation), sponsored by Fisher and Paykel Healthcare, and has received research grants from Fisher and Paykel Healthcare and lecture fees from Draeger Medical and GE Healthcare. Dr Mancebo reports the following: Covidien and Maquet_research support; Faron-steering committee member; Covidien and Hamilton-honoraria for speaking at a meeting. Dr. Navalesi's research laboratory has received equipment and grants from Maquet Critical Care, Draeger, and Intersurgical S.p.A. He has also received honoraria/speaking fees from Maquet Critical Care, Draeger, Breas, Philips, Resmed, and Hillrom. Dr Navalesi contributed to the development of the helmet Next, whose license for patent belongs to Intersurgical S.p.A., and receives royalties for that invention. Dr Quintel acts as advisor for Xenios and Baxter. CG, JGL, JJM, JMM, PM, and JLV declare no conflict of interest.

\section{References}

1. Quintel M, Tonetti T, Gattinoni L (2017) Will all ARDS patients be receiving mechanical ventilation in 2035 ? We are not sure. Intensive Care Med 43:573-574

2. Mosier JM, Joshi R, Hypes C, Pacheco G, Valenzuela T, Sakles JC (2015) The physiologically difficult airway. West J Emerg Med 16:1109-1117

3. Hypes C, Sakles J, Joshi R, Greenberg J, Natt B, Malo J, Bloom J, Chopra H, Mosier J (2016) Failure to achieve first attempt success at intubation using video laryngoscopy is associated with increased complications. Intern Emerg Med. doi:10.1007/s11739-016-1549-9

4. Perbet S, De Jong A, Delmas J, Futier E, Pereira B, Jaber S, Constantin JM (2015) Incidence of and risk factors for severe cardiovascular collapse after endotracheal intubation in the ICU: a multicenter observational study. Crit Care 19:257

5. Mosier JM, Hypes CD, Sakles JC (2016) Understanding preoxygenation and apneic oxygenation during intubation in the critically ill. Intensive Care Med 43(2):226-228

6. Baillard C, Fosse JP, Sebbane M, Chanques G, Vincent F, Courouble P, Cohen Y, Eledjam JJ, Adnet F, Jaber S (2006) Noninvasive ventilation improves preoxygenation before intubation of hypoxic patients. Am J Respir Crit Care Med 174:171-177

7. Miguel-Montanes R, Hajage D, Messika J, Bertrand F, Gaudry S, Rafat C, Labbe V, Dufour N, Jean-Baptiste S, Bedet A, Dreyfuss D, Ricard JD (2015) Use of high-flow nasal cannula oxygen therapy to prevent desaturation during tracheal intubation of intensive care patients with mild-tomoderate hypoxemia. Crit Care Med 43:574-583

8. Vourc'h M, Asfar P, Volteau C, Bachoumas K, Clavieras N, Egreteau PY, Asehnoune K, Mercat A, Reignier J, Jaber S, Prat G, Roquilly A, Brule N, Villers D, Bretonniere C, Guitton C (2015) High-flow nasal cannula oxygen during endotracheal intubation in hypoxemic patients: a randomized controlled clinical trial. Intensive Care Med 41(9):1538-1548

9. Papazian L, Corley A, Hess D, Fraser JF, Frat JP, Guitton C, Jaber S, Maggiore SM, Nava S, Rello J, Ricard JD, Stephan F, Trisolini R, Azoulay E (2016) Use of high-flow nasal cannula oxygenation in ICU adults: a narrative review. Intensive Care Med 42:1336-1349

10. Koenig SJ, Lakticova V, Mayo PH (2011) Utility of ultrasonography for detection of gastric fluid during urgent endotracheal intubation. Intensive Care Med 37:627-631
11. Jaber S, Jung $B$, Corne P, Sebbane M, Muller L, Chanques G, Verzilli $D$, Jonquet O, Eledjam JJ, Lefrant JY (2010) An intervention to decrease complications related to endotracheal intubation in the intensive care unit: a prospective, multiple-center study. Intensive Care Med 36:248-255

12. Koenig SJ, Lakticova V, Narasimhan M, Doelken P, Mayo PH (2015) Safety of propofol as an induction agent for urgent endotracheal intubation in the medical intensive care unit. J Intensive Care Med 30:499-504

13. Mosier JM, Sakles JC, Stolz U, Hypes CD, Chopra H, Malo J, Bloom JW (2015) Neuromuscular blockade improves first-attempt success for intubation in the intensive care unit. A propensity matched analysis. Ann Am Thorac Soc 12:734-741

14. Jaber S, Monnin M, Girard M, Conseil M, Cisse M, Carr J, Mahul M, Delay JM, Belafia F, Chanques G, Molinari N, De Jong A (2016) Apnoeic oxygenation via high-flow nasal cannula oxygen combined with non-invasive ventilation preoxygenation for intubation in hypoxaemic patients in the intensive care unit: the single-centre, blinded, randomised controlled OPTINIV trial. Intensive Care Med 42:1877-1887

15. De Jong A, Molinari N, Conseil M, Coisel Y, Pouzeratte Y, Belafia F, Jung B, Chanques G, Jaber S (2014) Video laryngoscopy versus direct laryngoscopy for orotracheal intubation in the intensive care unit: a systematic review and meta-analysis. Intensive Care Med 40:629-639

16. De Jong A, Molinari N, Conseil M, Coisel Y, Pouzeratte Y, Belafia F, Jung B, Chanques $G$, Jaber S (2014) Video laryngoscopy versus direct laryngoscopy for orotracheal intubation in the intensive care unit: a systematic review and meta-analysis. Intensive Care Med 40(5):629-639

17. Hypes CD, Stolz U, Sakles JC, Joshi RR, Natt B, Malo J, Bloom JW, Mosier JM (2016) Video laryngoscopy improves odds of first-attempt success at intubation in the intensive care unit. A propensity-matched analysis. Ann Am Thorac Soc 13:382-390

18. Lascarrou JB, Boisrame-Helms J, Bailly A, Le Thuaut A, Kamel T, Mercier E, Ricard JD, Lemiale V, Colin G, Mira JP, Meziani F, Messika J, Dequin PF, Boulain T, Azoulay E, Champigneulle B, Reignier J (2017) Video laryngoscopy vs direct laryngoscopy on successful first-pass orotracheal intubation among ICU patients: A randomized clinical trial. JAMA 317(5):483-493

19. De Jong A, Jung B, Daurat A, Chanques G, Mahul M, Monnin M, Molinari $N$, Jaber S (2016) Effect of rapid response systems on hospital mortality: a systematic review and meta-analysis. Intensive Care Med 42:615-617

20. Jung B, Daurat A, De Jong A, Chanques G, Mahul M, Monnin M, Molinari $\mathrm{N}$, Jaber S (2016) Rapid response team and hospital mortality in hospitalized patients. Intensive Care Med 42:494-504

21. Girou E, Schortgen F, Delclaux C, Brun-Buisson C, Blot F, Lefort Y, Lemaire F, Brochard L (2000) Association of noninvasive ventilation with nosocomial infections and survival in critically ill patients. JAMA 284:2361-2367

22. Mehta S, Hill NS (2001) Noninvasive ventilation. Am J Respir Crit Care Med 163:540-577

23. Kwok H, McCormack J, Cece R, Houtchens J, Hill NS (2003) Controlled trial of oronasal versus nasal mask ventilation in the treatment of acute respiratory failure. Crit Care Med 31:468-473

24. Nava S, Navalesi P, Gregoretti C (2009) Interfaces and humidification for noninvasive mechanical ventilation. Respir Care 54:71-84

25. Nava S, Navalesi P, Conti G (2006) Time of non-invasive ventilation. Intensive Care Med 32:361-370

26. Lightowler JV, Wedzicha JA, Elliott MW, Ram FS (2003) Non-invasive positive pressure ventilation to treat respiratory failure resulting from exacerbations of chronic obstructive pulmonary disease: Cochrane systematic review and meta-analysis. BMJ 326:185

27. Vital FM, Ladeira MT, Atallah AN (2013) Non-invasive positive pressure ventilation (CPAP or bilevel NPPV) for cardiogenic pulmonary oedema. Cochrane Database Syst Rev 5:CD005351

28. Lin C, Yu H, Fan H, Li Z (2014) The efficacy of noninvasive ventilation in managing postextubation respiratory failure: a meta-analysis. Heart Lung 43:99-104

29. Burns KE, Meade MO, Premji A, Adhikari NK (2014) Noninvasive ventilation as a weaning strategy for mechanical ventilation in adults with respiratory failure: a Cochrane systematic review. CMAJ 186:E112-E122

30. Hernandez G, Vaquero C, Colinas L, Cuena R, Gonzalez P, Canabal A, Sanchez S, Rodriguez ML, Villasclaras A, Fernandez R (2016) Effect of postextubation high-flow nasal cannula vs noninvasive ventilation on reintubation and postextubation respiratory failure in high-risk patients: a randomized clinical trial. JAMA 316:1565-1574 
31. Jaber $S$, Lescot T, Futier E, Paugam-Burtz C, Seguin P, Ferrandiere M, Lasocki S, Mimoz O, Hengy B, Sannini A, Pottecher J, Abback PS, Riu B, Belafia F, Constantin JM, Masseret E, Beaussier M, Verzilli D, De Jong A, Chanques G, Brochard L, Molinari N (2016) Effect of noninvasive ventilation on tracheal reintubation among patients with hypoxemic respiratory failure following abdominal surgery: a randomized clinical trial. JAMA 315:1345-1353

32. Hernandez G, Fernandez R, Lopez-Reina P, Cuena R, Pedrosa A, Ortiz R, Hiradier $P$ (2010) Noninvasive ventilation reduces intubation in chest trauma-related hypoxemia: a randomized clinical trial. Chest 137:74-80

33. Demoule A, Hill N, Navalesi P (2016) Can we prevent intubation in patients with ARDS? Intensive Care Med 42:768-771

34. Bellani G, Laffey JG, Pham T, Madotto F, Fan E, Brochard L, Esteban A, Gattinoni L, Bumbasirevic V, Piquilloud L, van Haren F, Larsson A, McAuley DF, Bauer PR, Arabi YM, Ranieri M, Antonelli M, Rubenfeld GD, Thompson BT, Wrigge H, Slutsky AS, Pesenti A (2017) Noninvasive ventilation of patients with acute respiratory distress syndrome. Insights from the LUNG SAFE study. Am J Respir Crit Care Med 195:67-77

35. Acute Respiratory Distress Syndrome Network, Brower RG, Matthay MA, Morris A, Schoenfeld D, Thompson BT, Wheeler A (2000) Ventilation with lower tidal volumes as compared with traditional tidal volumes for acute lung injury and the acute respiratory distress syndrome. $N$ Engl J Med 342:1301-1308

36. Amato MB, Meade MO, Slutsky AS, Brochard L, Costa EL, Schoenfeld DA, Stewart TE, Briel M, Talmor D, Mercat A, Richard JC, Carvalho CR, Brower RG (2015) Driving pressure and survival in the acute respiratory distress syndrome. N Engl J Med 372:747-755

37. Laffey JG, Bellani G, Pham T, Fan E, Madotto F, Bajwa EK, Brochard L, Clarkson K, Esteban A, Gattinoni L, van Haren F, Heunks LM, Kurahashi K, Laake JH, Larsson A, McAuley DF, McNamee L, Nin N, Qiu H, Ranieri M, Rubenfeld GD, Thompson BT, Wrigge H, Slutsky AS, Pesenti A (2016) Potentially modifiable factors contributing to outcome from acute respiratory distress syndrome: the LUNG SAFE study. Intensive Care Med 42:1865-1876

38. Bellani G, Laffey JG, Pham T, Fan E, Brochard L, Esteban A, Gattinoni L, van Haren F, Larsson A, McAuley DF, Ranieri M, Rubenfeld G, Thompson BT, Wrigge H, Slutsky AS, Pesenti A (2016) Epidemiology, patterns of care, and mortality for patients with acute respiratory distress syndrome in intensive care units in 50 countries. JAMA 315:788-800

39. Brower RG, Lanken PN, Maclntyre N, Matthay MA, Morris A, Ancukiewicz M, Schoenfeld D, Thompson BT (2004) Higher versus lower positive end-expiratory pressures in patients with the acute respiratory distress syndrome. N Engl J Med 351:327-336

40. Mercat A, Richard JC, Vielle B, Jaber S, Osman D, Diehl JL, Lefrant JY, Prat G, Richecoeur J, Nieszkowska A, Gervais C, Baudot J, Bouadma L, Brochard L (2008) Positive end-expiratory pressure setting in adults with acute lung injury and acute respiratory distress syndrome: a randomized controlled trial. JAMA 299:646-655

41. Meade MO, Cook DJ, Guyatt GH, Slutsky AS, Arabi YM, Cooper DJ, Davies AR, Hand LE, Zhou Q, Thabane L, Austin P, Lapinsky S, Baxter A, Russell J, Skrobik Y, Ronco JJ, Stewart TE (2008) Ventilation strategy using low tidal volumes, recruitment maneuvers, and high positive end-expiratory pressure for acute lung injury and acute respiratory distress syndrome: a randomized controlled trial. JAMA 299:637-645

42. Briel M, Meade M, Mercat A, Brower RG, Talmor D, Walter SD, Slutsky AS, Pullenayegum E, Zhou Q, Cook D, Brochard L, Richard JC, Lamontagne F, Bhatnagar N, Stewart TE, Guyatt G (2010) Higher vs lower positive end-expiratory pressure in patients with acute lung injury and acute respiratory distress syndrome: systematic review and meta-analysis. JAMA 303:865-873

43. Ferguson ND, Fan E, Camporota L, Antonelli M, Anzueto A, Beale R, Brochard L, Brower R, Esteban A, Gattinoni L, Rhodes A, Slutsky AS, Vincent $J$, Rubenfeld GD, Thompson BT, Ranieri VM (2012) The Berlin definition of ARDS: an expanded rationale, justification, and supplementary material. Intensive Care Med 38:1573-1582

44. Goligher EC, Kavanagh BP, Rubenfeld GD, Adhikari NK, Pinto R, Fan E, Brochard LJ, Granton JT, Mercat A, Marie Richard JC, Chretien JM, Jones GL, Cook DJ, Stewart TE, Slutsky AS, Meade MO, Ferguson ND (2014) Oxygenation response to positive end-expiratory pressure predicts mortality in acute respiratory distress syndrome. A secondary analysis of the LOVS and ExPress trials. Am J Respir Crit Care Med 190:70-76
45. Fan E, Wilcox ME, Brower RG, Stewart TE, Mehta S, Lapinsky SE, Meade MO, Ferguson ND (2008) Recruitment maneuvers for acute lung injury: a systematic review. Am J Respir Crit Care Med 178:1156-1163

46. Chacko B, Peter JV, Tharyan P, John G, Jeyaseelan L (2015) Pressure-controlled versus volume-controlled ventilation for acute respiratory failure due to acute lung injury (ALI) or acute respiratory distress syndrome (ARDS). Cochrane Database Syst Rev 1:008807

47. Ferguson ND, Cook DJ, Guyatt GH, Mehta S, Hand L, Austin P, Zhou Q, Matte A, Walter SD, Lamontagne F, Granton JT, Arabi YM, Arroliga AC, Stewart TE, Slutsky AS, Meade MO (2013) High-frequency oscillation in early acute respiratory distress syndrome. N Engl J Med 368:795-805

48. Young D, Lamb SE, Shah S, MacKenzie I, Tunnicliffe W, Lall R, Rowan K, Cuthbertson BH (2013) High-frequency oscillation for acute respiratory distress syndrome. N Engl J Med 368:806-813

49. Guerin C, Reignier J, Richard JC, Beuret P, Gacouin A, Boulain T, Mercier E, Badet M, Mercat A, Baudin O, Clavel M, Chatellier D, Jaber S, Rosselli S, Mancebo J, Sirodot M, Hilbert G, Bengler C, Richecoeur J, Gainnier M, Bayle F, Bourdin G, Leray V, Girard R, Baboi L, Ayzac L (2013) Prone positioning in severe acute respiratory distress syndrome. N Engl J Med 368:2159-2168

50. Papazian L, Forel JM, Gacouin A, Penot-Ragon C, Perrin G, Loundou A, Jaber S, Arnal JM, Perez D, Seghboyan JM, Constantin JM, Courant P, Lefrant JY, Guerin C, Prat G, Morange S, Roch A (2010) Neuromuscular blockers in early acute respiratory distress syndrome. N Engl J Med 363:1107-1116

51. Boles JM, Bion J, Connors A, Herridge M, Marsh B, Melot C, Pearl R, Silverman $\mathrm{H}$, Stanchina M, Vieillard-Baron A, Welte T (2007) Weaning from mechanical ventilation. Eur Respir J 29:1033-1056

52. Beduneau G, Pham T, Schortgen F, Piquilloud L, Zogheib E, Jonas M, Grelon F, Runge I, Terzi N, Grange S, Barberet G, Guitard PG, Frat JP, Constan A, Chretien JM, Mancebo J, Mercat A, Richard JM, Brochard L (2016) Epidemiology of weaning outcome according to a new definition. The WIND study. Am J Respir Crit Care Med 195(6):772-783

53. Ouellette DR, Patel S, Girard TD, Morris PE, Schmidt GA, Truwit JD, Al-Hazzani W, Burns SM, Epstein SK, Esteban A, Fan E, Ferrer M, Fraser GL, Gong M, Hough CL, Mehta S, Nanchal R, Pawlik AJ, Schweickert W, Sessler CN, Strom T, Kress JP (2017) Liberation from mechanical ventilation: an official American College of Chest Physicians/American Thoracic Society clinical practice guideline: inspiratory pressure augmentation during spontaneous breathing trials, protocols minimizing sedation, and non-invasive ventilation immediately after extubation. Chest 151:166-180

54. Frat JP, Thille AW, Mercat A, Girault C, Ragot S, Perbet S, Prat G, Boulain T, Morawiec E, Cottereau A, Devaquet J, Nseir S, Razazi K, Mira JP, Argaud L, Chakarian JC, Ricard JD, Wittebole X, Chevalier S, Herbland A, Fartoukh M, Constantin JM, Tonnelier JM, Pierrot M, Mathonnet A, Beduneau G, Deletage-Metreau C, Richard JC, Brochard L, Robert R (2015) High-flow oxygen through nasal cannula in acute hypoxemic respiratory failure. N Engl J Med 372:2185-2196

55. Patel BK, Wolfe KS, Pohlman AS, Hall JB, Kress JP (2016) Effect of noninvasive ventilation delivered by helmet vs face mask on the rate of endotracheal intubation in patients with acute respiratory distress syndrome: a randomized clinical trial. JAMA 315:2435-244

56. Lemiale $V$, Resche-Rigon M, Mokart D, Pene F, Argaud L, Mayaux J, Guitton C, Rabbat A, Girault C, Kouatchet A, Vincent F, Bruneel F, Nyunga M, Seguin A, Klouche K, Colin G, Kontar L, Perez P, Meert AP, Benoit DD, Papazian L, Demoule A, Chevret S, Azoulay E (2016) Highflow nasal cannula oxygenation in immunocompromised patients with acute hypoxemic respiratory failure: a Groupe de Recherche Respiratoire en Reanimation Onco-Hematologique study. Crit Care Med 45(3):e274-e280

57. Lemiale V, Mokart D, Resche-Rigon M, Pene F, Mayaux J, Faucher E, Nyunga M, Girault C, Perez P, Guitton C, Ekpe K, Kouatchet A, Theodose I, Benoit D, Canet E, Barbier F, Rabbat A, Bruneel F, Vincent F, Klouche K, Loay K, Mariotte E, Bouadma L, Moreau AS, Seguin A, Meert AP, Reignier J, Papazian L, Mehzari I, Cohen Y, Schenck M, Hamidfar R, Darmon M, Demoule A, Chevret S, Azoulay E (2015) Effect of noninvasive ventilation vs oxygen therapy on mortality among immunocompromised patients with acute respiratory failure: a randomized clinical trial. JAMA 314:1711-1719 
58. Coudroy R, Jamet A, Petua P, Robert R, Frat JP, Thille AW (2016) Highflow nasal cannula oxygen therapy versus noninvasive ventilation in immunocompromised patients with acute respiratory failure: an observational cohort study. Ann Intensive Care 6:45

59. Hernandez G, Vaquero C, GonzalezP, Subira C, Frutos-Vivar F, Rialp G, Laborda C, Colinas L, Cuena R, Fernandez R (2016) Effect of postextubation highflow nasal cannula vs conventional oxygen therapy on reintubation in low-risk patients: a randomized clinical trial. JAMA 315:1354-1361

60. Gattinoni L, Tonetti T, Cressoni M, Cadringher P, Herrmann P, Moerer O, Protti A, Gotti M, Chiurazzi C, Carlesso E, Chiumello D, Quintel M (2016) Ventilator-related causes of lung injury: the mechanical power. Intensive Care Med 42:1567-1575

61. Yoshida T, Fujino Y, Amato MB, Kavanagh BP (2017) Spontaneous breathing during mechanical ventilation — risks, mechanisms and management. Am J Respir Crit Care Med 195(8):985-992

62. Georgopoulos D, Xirouchaki N, Tzanakis N, Younes M (2016) Driving pressure during assisted mechanical ventilation: is it controlled by patient brain? Respir Physiol Neurobiol 228:69-75

63. Blanch L, Villagra A, Sales B, Montanya J, Lucangelo U, Lujan M, Garcia Esquirol O, Chacon E, Estruga A, Oliva JC, Hernandez-Abadia A, Albaiceta GM, Fernandez-Mondejar E, Fernandez R, Lopez-Aguilar J, Villar J, Murias G, Kacmarek RM (2015) Asynchronies during mechanical ventilation are associated with mortality. Intensive Care Med 41:633-641

64. Vaporidi K, Babalis D, Chytas A, Lilitsis E, Kondili E, Amargianitakis V, Chouvarda I, Maglaveras N, Georgopoulos D (2016) Clusters of ineffective efforts during mechanical ventilation: impact on outcome. Intensive Care Med 43(2):184-191

65. Conti G, Ranieri VM, Costa R, Garratt C, Wighton A, Spinazzola G, Urbino R, Mascia L, Ferrone G, Pohjanjousi P, Ferreyra G, Antonelli M (2016) Effects of dexmedetomidine and propofol on patient-ventilator interaction in difficult-to-wean, mechanically ventilated patients: a prospective, open-label, randomised, multicentre study. Crit Care 20:206

66. Celli BR, MacNee W, Force AET (2004) Standards for the diagnosis and treatment of patients with COPD: a summary of the ATS/ERS position paper. Eur Respir J 23:932-946

67. Alia I, de la Cal MA, Esteban A, Abella A, Ferrer R, Molina FJ, Torres A, Gordo F, Elizalde JJ, de Pablo R, Huete A, Anzueto A (2011) Efficacy of corticosteroid therapy in patients with an acute exacerbation of chronic obstructive pulmonary disease receiving ventilatory support Arch Intern Med 171:1939-1946

68. Abroug F, Ouanes-Besbes L, Fkih-Hassen M, Ouanes I, Ayed S, Dachraoui F, Brochard L, Elatrous S (2014) Prednisone in COPD exacerbation requiring ventilatory support: an open-label randomised evaluation. Eur Respir J 43:717-724

69. Abroug F, Ouanes I, Abroug S, Dachraoui F, Abdallah SB, Hammouda Z, Ouanes-Besbes $L$ (2014) Systemic corticosteroids in acute exacerbation of COPD: a meta-analysis of controlled studies with emphasis on ICU patients. Ann Intensive Care 4:32

70. Demoule A, Chevret S, Carlucci A, Kouatchet A, Jaber S, Meziani F, Schmidt M, Schnell D, Clergue C, Aboab J, Rabbat A, Eon B, Guerin C, Georges H, Zuber B, Dellamonica J, Das V, Cousson J, Perez D, Brochard L, Azoulay E, oVNI Study Group; REVA Network (Research Network in Mechanical Ventilation) (2016) Changing use of noninvasive ventilation in critically ill patients: trends over 15 years in francophone countries. Intensive Care Med 42:82-92

71. Hilbert G, Gruson D, Vargas F, Valentino R, Gbikpi-Benissan G, Dupon M, Reiffers J, Cardinaud JP (2001) Noninvasive ventilation in immunosuppressed patients with pulmonary infiltrates, fever, and acute respiratory failure. N Engl J Med 344:481-487

72. Antonelli M, Conti G, Bufi M, Costa MG, Lappa A, Rocco M, Gasparetto A, Meduri GU (2000) Noninvasive ventilation for treatment of acute respiratory failure in patients undergoing solid organ transplantation: a randomized trial. JAMA 283:235-241

73. Froese $A B$ (1997) High-frequency oscillatory ventilation for adult respiratory distress syndrome: let's get it right this time! Crit Care Med 25:906-908

74. Derdak S, Mehta S, Stewart TE, Smith T, Rogers M, Buchman TG, Carlin B, Lowson S, Granton J, Multicenter Oscillatory Ventilation For Acute Respiratory Distress Syndrome Trial Study I (2002) High-frequency oscillatory ventilation for acute respiratory distress syndrome in adults: a randomized, controlled trial. Am J Respir Crit Care Med 166:801-808
75. Ferguson ND, Cook DJ, Guyatt GH, Mehta S, Hand L, Austin P, Zhou Q, Matte A, Walter SD, Lamontagne F, Granton JT, Arabi YM, Arroliga AC, Stewart TE, Slutsky AS, Meade MO, OSCILLATE Trial Investigators, Canadian Critical Care Trials Group (2013) High-frequency oscillation in early acute respiratory distress syndrome. N Engl J Med 368:795-805

76. Young D, Lamb SE, Shah S, MacKenzie I, Tunnicliffe W, Lall R, Rowan K, Cuthbertson BH, OSCAR Study Group (2013) High-frequency oscillation for acute respiratory distress syndrome. N Engl J Med 368:806-813

77. Freeman BD, Morris PE (2012) Tracheostomy practice in adults with acute respiratory failure. Crit Care Med 40:2890-2896

78. Simon M, Metschke M, Braune SA, Puschel K, Kluge S (2013) Death after percutaneous dilatational tracheostomy: a systematic review and analysis of risk factors. Crit Care 17:R258

79. Vargas M, Sutherasan Y, Antonelli M, Brunetti I, Corcione A, Laffey JG, Putensen C, Servillo G, Pelosi P (2015) Tracheostomy procedures in the intensive care unit: an international survey. Crit Care 19:291

80. Terragni PP, Antonelli M, Fumagalli R, Faggiano C, Berardino M, Pallavicini FB, Miletto A, Mangione S, Sinardi AU, Pastorelli M, Vivaldi N, Pasetto A, Della Rocca G, Urbino R, Filippini C, Pagano E, Evangelista A, Ciccone G, Mascia L, Ranieri VM (2010) Early vs late tracheotomy for prevention of pneumonia in mechanically ventilated adult ICU patients: a randomized controlled trial. JAMA 303:1483-1489

81. Dreyfuss D, Saumon G (1998) Ventilator-induced lung injury: lessons from experimental studies. Am J Respir Crit Care Med 157:294-323

82. Engoren M, Arslanian-Engoren C, Fenn-Buderer N (2004) Hospital and long-term outcome after tracheostomy for respiratory failure. Chest 125:220-227

83. Slutsky AS, Ranieri VM (2013) Ventilator-induced lung injury. N Engl J Med 369:2126-2136

84. Bello G, De Pascale G, Antonelli M (2016) Noninvasive ventilation. Clin Chest Med 37:711-721

85. Esteban A, Frutos-Vivar F, Ferguson ND, Arabi Y, Apezteguia C, Gonzalez M, Epstein SK, Hill NS, Nava S, Soares MA, D’Empaire G, Alia I, Anzueto A (2004) Noninvasive positive-pressure ventilation for respiratory failure after extubation. N Engl J Med 350:2452-2460

86. Braune $S$, Sieweke A, Brettner F, Staudinger T, Joannidis M, Verbrugge $S$, Frings D, Nierhaus A, Wegscheider K, Kluge S (2016) The feasibility and safety of extracorporeal carbon dioxide removal to avoid intubation in patients with COPD unresponsive to noninvasive ventilation for acute hypercapnic respiratory failure (ECLAIR study): multicentre case-control study. Intensive Care Med 42:1437-1444

87. Del Sorbo L, Pisani L, Filippini C, Fanelli V, Fasano L, Terragni P, Dell'Amore A, Urbino R, Mascia L, Evangelista A, Antro C, D'Amato R, Sucre MJ, Simonetti U, Persico P, Nava S, Ranieri VM (2015) Extracorporeal CO2 removal in hypercapnic patients at risk of noninvasive ventilation failure: a matched cohort study with historical control. Crit Care Med 43:1 20-127

88. Koestler A, Smythies JR (1969) Beyond reductionism: new perspectives in the life sciences. Hutchinson, London

89. Berry D (2011) Adaptive clinical trials: the promise and the caution. J Clin Oncol 20:606-609

90. Marini JJ, Vincent JL, Annane D (2015) Critical care evidence-new directions. JAMA 313:893-894

91. Yoshida T, Roldan R, Beraldo MA, Torsani V, Gomes S, De Santis RR, Costa EL, Tucci MR, Lima RG, Kavanagh BP, Amato MB (2016) Spontaneous effort during mechanical ventilation: maximal injury with less positive end-expiratory pressure. Crit Care Med 44:e678-e688

92. Cornejo RA, Diaz JC, Tobar EA, Bruhn AR, Ramos CA, Gonzalez RA, Repetto CA, Romero CM, Galvez LR, Llanos O, Arellano DH, Neira WR, Diaz GA, Zamorano AJ, Pereira GL (2013) Effects of prone positioning on lung protection in patients with acute respiratory distress syndrome. Am J Respir Crit Care Med 188:440-448

93. Guerin C, Moss M, Talmor D (2016) A glossary of ARDS for beginners Intensive Care Med 42:659-662

94. Marini JJ, Jaber S (2016) Dynamic predictors of VILI risk: beyond the driving pressure. Intensive Care Med 42:1597-1600

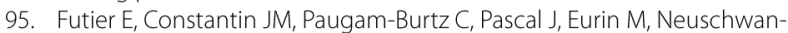
$\operatorname{der}$ A, Marret E, Beaussier M, Gutton C, Lefrant JY, Allaouchiche B, Verzilli D, Leone M, De Jong A, Bazin JE, Pereira B, Jaber S (2013) A trial of intraoperative low-tidal-volume ventilation in abdominal surgery. $N$ Engl J Med 369:428-437 
96. Gattinoni L, Giomarelli P (2015) Acquiring knowledge in intensive care: merits and pitfalls of randomized controlled trials. Intensive Care Med 41:1460-1464

97. Ghassemi M, Celi LA, Stone DJ (2015) State of the art review: the data revolution in critical care. Crit Care 19:118

98. Ahasic AM, Christiani DC (2015) Personalized critical care medicine: how far away are we? Semin Respir Crit Care Med 36:809-822

99. Tipping CJ, Harrold M, Holland A, Romero L, Nisbet T, Hodgson CL (2017) The effects of active mobilisation and rehabilitation in ICU on mortality and function: a systematic review. Intensive Care Med 43(2):171-183

100. Girardis M, Busani S, Damiani E, Donati A, Rinaldi L, Marudi A, Morelli A, Antonelli M, Singer M (2016) Effect of conservative vs conventional oxygen therapy on mortality among patients in an intensive care unit: the oxygen-ICU randomized clinical trial. JAMA 316:1583-1589
101. Marini JJ (2013) Too much for too long-wrong targets, wrong timing? Crit Care Med 41:664-665

102. Beitler JR, Sands SA, Loring SH, Owens RL, Malhotra A, Spragg RG, Matthay MA, Thompson BT, Talmor D (2016) Quantifying unintended exposure to high tidal volumes from breath stacking dyssynchrony in ARDS: the BREATHE criteria. Intensive Care Med 42:1427-1436

103. Talmor D, Sarge T, Malhotra A, O'Donnell CR, Ritz R, Lisbon A, Novack V, Loring SH (2008) Mechanical ventilation guided by esophageal pressure in acute lung injury. N Engl J Med 359:2095-2104

104. Nelson JE, Cox CE, Hope AA, Carson SS (2010) Chronic critical illness. Am J Respir Crit Care Med 182:446-454

105. Kassis EB, Loring SH, Talmor D et al (2016) Is transpulmonary pressureguided PEEP titration really optimal? Response to Yamaga. Intensive Care Med 42:1847-1848 